\title{
Optimization of GMAW Process Parameters to Improve the Length of Penetration in EN 10025 S 235 Grade
}

\author{
M. U. Deshpande*, ${ }^{*}$, J. M. Kshirsagar* and Dr. H. M. Dharmadhikari* \\ *Department of Mechanical Engineering, Maharashtra Institute of Technology, \\ Aurangabad, Maharashtra, 431028, India
}

†Corresponding author : mauktikdeshpande@gmail.com

(Received June 27, 2016 ; Revised August 31, 2016 ; Accepted December 13, 2016)

\begin{abstract}
In auto ancillary fabrication industry, GMAW is a very useful \& important welding process and EN10025 S 235 Grade is common material used for manufacturing of two wheeler chassis. This research gives the detail influence of welding process parameters such as welding current, welding voltage, wire speed on the penetration in EN10025 S 235 Grade mild steel material. The experimentation of this research has been carried out by using three factors, three level Taguchi DOE method. To analyze \& optimize the welding parameters \& characteristics, analysis of variance, L9 orthogonal array \& signal to noise ratio are used. Length of Penetration in addition to the depth of penetration is major concern in fillet welded joints, as the penetration decides the strength of the welded joint. After analysis of penetration in all 9 welded samples, optimize parameters readings verified \& found probability value within 0.05 .From this research it is come to know that welding current $\&$ welding voltage is major parameters which affects the penetration in welded joints.
\end{abstract}

Key Words : GMAW, Length of penetration, Optimization, Taguchi DOE, Voltage, Welding current.

\section{Introduction}

Gas metal arc welding is a welding process which has various industrial applications. In GMAW an electric arc produced between electrode \& work piece metals, this causes electrode \& work piece metal to melt and join $^{1)}$. The joining area is called as weld ${ }^{4)}$. GMAW process parameters affecting the quality of welding \& productivity. In auto ancillary fabrication industry length of penetration is one of the most important factors which should achieve during welding. This Length of penetration is measured at depth of $\mathrm{T} / 20$ and minimum requirement of which is $0.8 \mathrm{xT}$ so as to get optimum weld strength where $\mathrm{T}$ is thickness of metal to be welded. The input parameters which are mainly responsible for welding penetration is welding current, welding voltage, welding speed $\&$ these parameters plays an important role in achieving the desired penetration in welded joints. In this research work, EN 10025 S 235 Grade mild steel material has been used with specimen size of $100 \times 80$ $\times 3 \mathrm{~mm}$.Design of experiments based on Taguchi tech- nique is used to evaluate the data. An orthogonal array, signal to noise $(\mathrm{S} / \mathrm{N})$ ratio and analysis of variance (ANOVA) has been used to find the best welding penetration in mild steel materials by using different range of input parameters.

We have used Taguchi DOE method for the experimentation as the method is an efficient method for optimization of process parameters. The method was developed by Dr. Genichi Taguchi, who was a Japanese quality management consultant; the method is based on orthogonal array experiments, which gives reduced optimum setting of process control parameters. The method was selected for the experimentation because the method is cost effective, less time consuming, greater accuracy, and robust design for large scale application. By using Taguchi method for process parameters optimization Design of Experiments (DOE) were selected. For the experimentation 3 factors \& 3 level Taguchi design model was used, Based on this model we have generated L9 orthogonal array \& total 9 runs were taken for the experiment. Minitab 15.0 software was used to generate the orthogonal array through Taguchi Design. 


\section{Experimental Procedure}

\subsection{Sample preparation}

We have used Gas Metal Arc Welding process for the experimentation, as the process has high weld deposition efficiency \& better weld quality with low operation cost. Experiments were carried out by using semiautomatic controlled GMAW processAK 600AMP welding machine.Copper coated steel wire of ER70 S6 grade with $0.8 \mathrm{~mm}$ diameter in the coil form was used for the welding. Shielding gas Ar-C02 used for shielding purpose with percentage of Ar: $82 \%$ \& $\mathrm{CO} 2: 18 \%{ }^{2}$.

Mild Steel plate EN10025 S 235 Grade used as base material with specimen size of $100 \times 80 \times 3 \mathrm{~mm}$. The welding is carried out in $2 \mathrm{~F}$ welding position \& the joint taken for welding was Tee joint. The welding is done by the qualified welder and is done as per the guidelines of EN ISO $15609-1^{3)}$.

\subsection{Experimental Procedure.}

\subsubsection{Selection of important process parameters}

The controllable process parameters ${ }^{6}$ ) were selected conduct the experiments are Current, Voltage \&Wire speed. The objective of this study as discussed earlier is to optimize the welding process parameters for enhancing weld penetration. A total of the three welding process parameters were chosen as the controlling factors.

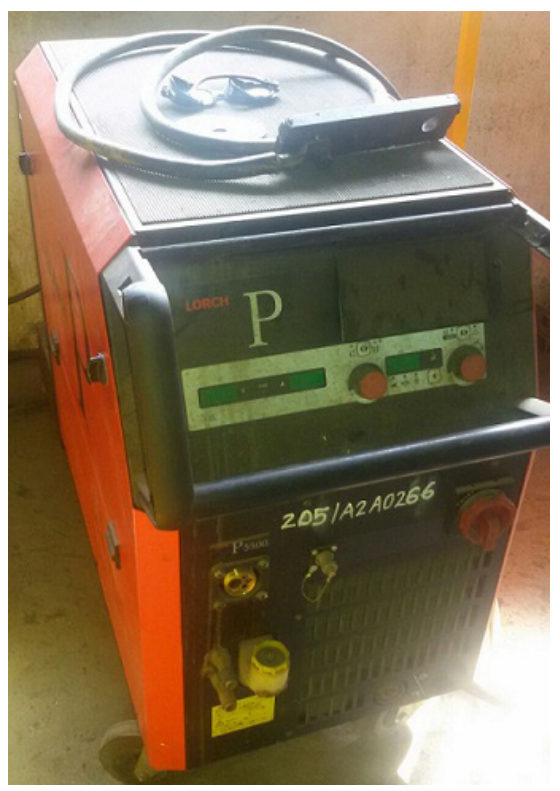

Fig. 1 Photographic view of GMA welding machine

Table 1 EN 10025 S 235 Grade Material Properties

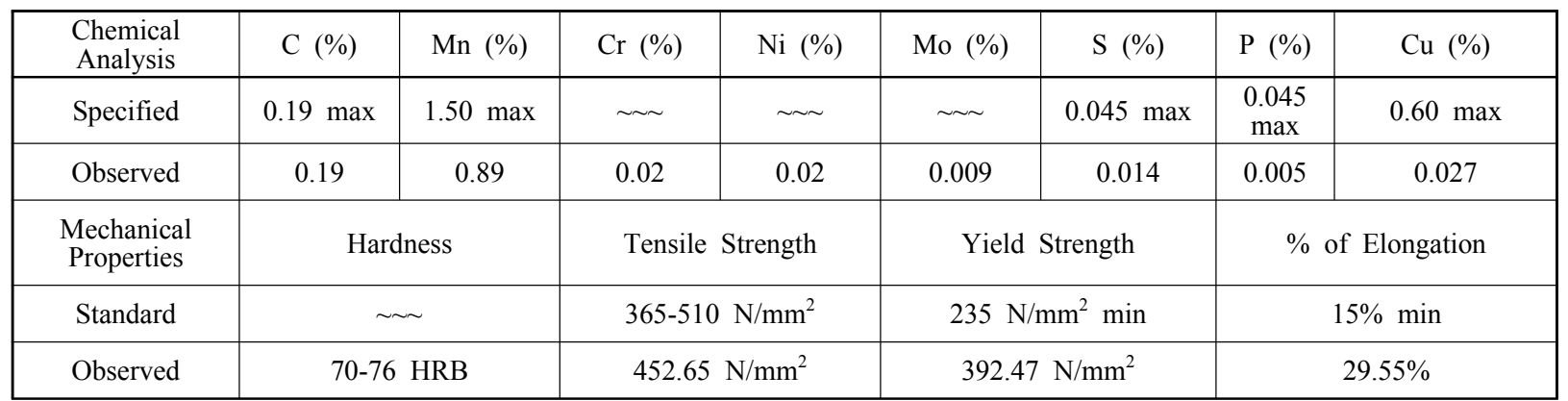

Table 2 Filler Wire Material Properties

\begin{tabular}{|c|c|c|c|c|c|c|}
\hline \multicolumn{7}{|c|}{ Material Description : Copper Coated Wire used in GMA Welding Process } \\
\hline \multicolumn{7}{|c|}{ Material Specification: American Welding Society A5.18 Grade ER70-S6 } \\
\hline \multicolumn{7}{|c|}{ Size : Dia.0.8 mm } \\
\hline $\begin{array}{l}\text { Chemical } \\
\text { Analysis }\end{array}$ & $\mathrm{C}(\%)$ & Mn $(\%)$ & $\mathrm{Si}(\%)$ & $\mathrm{S}(\%)$ & $\mathrm{P}(\%)$ & $\mathrm{Cu}(\%)$ \\
\hline Specified & $0.07-0.15$ & $1.40-1.85$ & $0.80-1.15$ & $0.035 \max$ & $0.025 \max$ & $0.50 \max$ \\
\hline Observed & 0.129 & 1.58 & 0.87 & 0.03 & 0.019 & 0.3 \\
\hline $\begin{array}{l}\text { Mechanical } \\
\text { Properties }\end{array}$ & \multicolumn{2}{|c|}{ UTS (Mpa) } & $\begin{array}{l}\text { Yield Strength } \\
(\mathrm{Mpa})\end{array}$ & Elongation $(\%)$ & $\begin{array}{c}\text { Impact } \\
\text { Properties } \\
\text { (CVN) } \\
\text { Average (J) }\end{array}$ & $\begin{array}{c}\text { Temperature } \\
\left({ }^{\circ} \mathrm{C}\right)\end{array}$ \\
\hline Standard & \multicolumn{2}{|c|}{480 Min } & 400 Min & 22 Min & 27 & -30 \\
\hline Observed & \multicolumn{2}{|c|}{1333.36} & 430 & 28.5 & 27 & -30 \\
\hline
\end{tabular}




\subsubsection{To decide the upper \& lower limits process parameters}

The selection of upper \& lower limit of process parameters has been done on the basis of machine manufacturer ESAB guideline \& standards which is based on filler wire diameter, shielding gas percentage $\&$ type of weld joint.

\subsubsection{Development of orthogonal array}

A matrix experiments consists of a set of experiments where the settings of the various products or process parameters are changed that which are to be studied from one experiment to another. After conducting a matrix experiment the data from all experiments in the set taken together are analyzed to determine the effects of several parameters. Conducting matrix experiments using special matrices, called Orthogonal Array ${ }^{7}$, allows the effects of several parameters to be determined efficiently and is an important technique in Parameter Design.

L9 orthogonal array ${ }^{5)}$ was developed by using 3 factors \& 3 levels Taguchi design.

Experimentation for the welding process as per the parameters mentioned in orthogonal array ${ }^{8}$

\subsubsection{Preparation of samples \& experimental trials}

Total 09 Nos. of trials conducted as defined in orthogonal array sampling plan, test piece used for the trials as per the defined size $(100 \times 80 \times 3 \mathrm{~mm})$

\subsubsection{Penetration inspection}

After preparation of all 09 Nos. of samples, length of penetration is measured by taking cut section of all samples \& using semi automatic micro graphical microscope (Rapid-I designed by Customised techonologies Bangalore, India ).

Microscope with embedded camera can be controlled and programmed using computer. For the ease of oper-

Table 3 Level of Process Parameters

\begin{tabular}{|c|c|c|c|}
\hline Levels & $\begin{array}{c}\text { Current } \\
(\mathrm{A})\end{array}$ & $\begin{array}{c}\text { Voltage } \\
(\mathrm{V})\end{array}$ & $\begin{array}{c}\text { Wire Speed } \\
(\mathrm{m} / \mathrm{min})\end{array}$ \\
\hline 1 & 160 & 16 & 8 \\
\hline 2 & 190 & 19 & 10 \\
\hline 3 & 220 & 22 & 12 \\
\hline
\end{tabular}

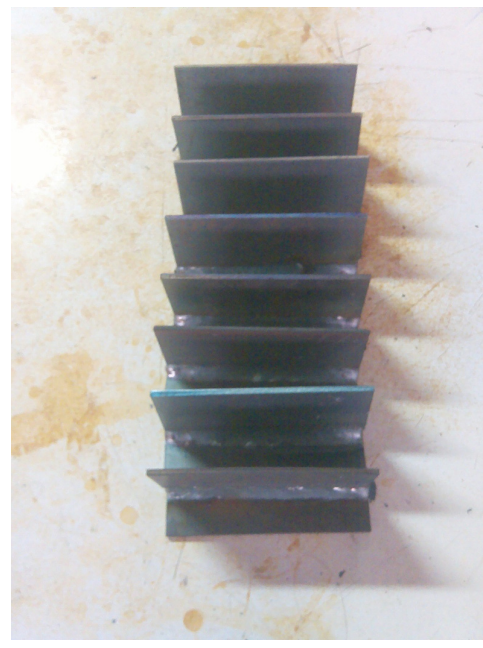

Fig. 2 Sample preparation

ation already saved program can be used and real time reports are generated in generic format.

\subsubsection{Analyze Taguchi design}

To analyze the Taguchi Design, Signal to Noise(S/N) ratio calculated ${ }^{5)}$. As we required maximum length of penetration as a result, larger is better option was selected. After experimentation, $\mathrm{S} / \mathrm{N}$ ratio calculated through the penetration reading.

Graph for the response table for SN Ratios \& Response table for Means can be plotted as follows

As it can be seen from main effects plot for SN ratio and main effects plot for means; favorable outcome i.e. optimal (maximum) length of penetration will be at a combination of A-1, B-2, C-3. If seen at combinations obtained through L-9 orthogonal array; there is no such combination exists as stated above, so for verification new sample is prepared with parameter combination as A-1 current 160 A, B-2 voltage $19 \mathrm{~V}$ and C-3 wire speed $12 \mathrm{~m} / \mathrm{min}$. And after doing routine procedure for penetration inspection; the length of penetration is observed as $7.2334 \mathrm{~mm}$ which is higher than the lengths of penetration observed earlier.

Thus from this we can say that optimal set of parameters to get optimal(maximum) length of penetration for EN 10025 S 235 grade material is 160 A current, 19V voltage and $12 \mathrm{~m} / \mathrm{min}$ wire speed.

Table 4 Sampling plan for process parameters as per taguchi method

\begin{tabular}{|c|c|c|c|c|c|c|c|c|c|}
\hline $\begin{array}{c}\text { Process } \\
\text { Parameter }\end{array}$ & Sample 1 & Sample 2 & Sample 3 & Sample 4 & Sample 5 & Sample 6 & Sample 7 & Sample 8 & Sample 9 \\
\hline $\begin{array}{c}\text { Current } \\
\text { (A) }\end{array}$ & 160 & 160 & 160 & 190 & 190 & 190 & 220 & 220 & 220 \\
\hline $\begin{array}{c}\text { Voltage } \\
\text { (V) }\end{array}$ & 16 & 19 & 22 & 16 & 19 & 22 & 16 & 19 & 22 \\
\hline $\begin{array}{c}\text { Wire Speed } \\
\text { (M/min) }\end{array}$ & 8 & 10 & 12 & 10 & 12 & 8 & 12 & 8 & 10 \\
\hline
\end{tabular}


Table 5 S/N Ratio calculation

\begin{tabular}{|c|c|c|c|c|c|c|}
\hline \multicolumn{7}{|c|}{ ORTHOGONAL ARRAY AND CORROSPONDING RESULTS } \\
\hline Sr No & A & B & C & length of pentration & SNRA1 & MEAN1 \\
\hline 1 & 1 & 1 & 1 & 4.5274 & 13.1170 & 4.5274 \\
\hline 2 & 1 & 2 & 2 & 6.1288 & 15.7475 & 6.1288 \\
\hline 3 & 1 & 3 & 3 & 6.1099 & 15.7207 & 6.1099 \\
\hline 4 & 2 & 1 & 2 & 4.5093 & 13.0822 & 4.5093 \\
\hline 5 & 2 & 2 & 3 & 5.8477 & 15.3397 & 5.8477 \\
\hline 6 & 2 & 3 & 1 & 3.88 & 11.7766 & 3.8800 \\
\hline 7 & 3 & 1 & 3 & 4.1005 & 12.2567 & 4.1005 \\
\hline 8 & 3 & 2 & 1 & 3.8904 & 11.7999 & 3.8904 \\
\hline 9 & 3 & 3 & 2 & 3.7589 & 11.5012 & 3.7589 \\
\hline
\end{tabular}

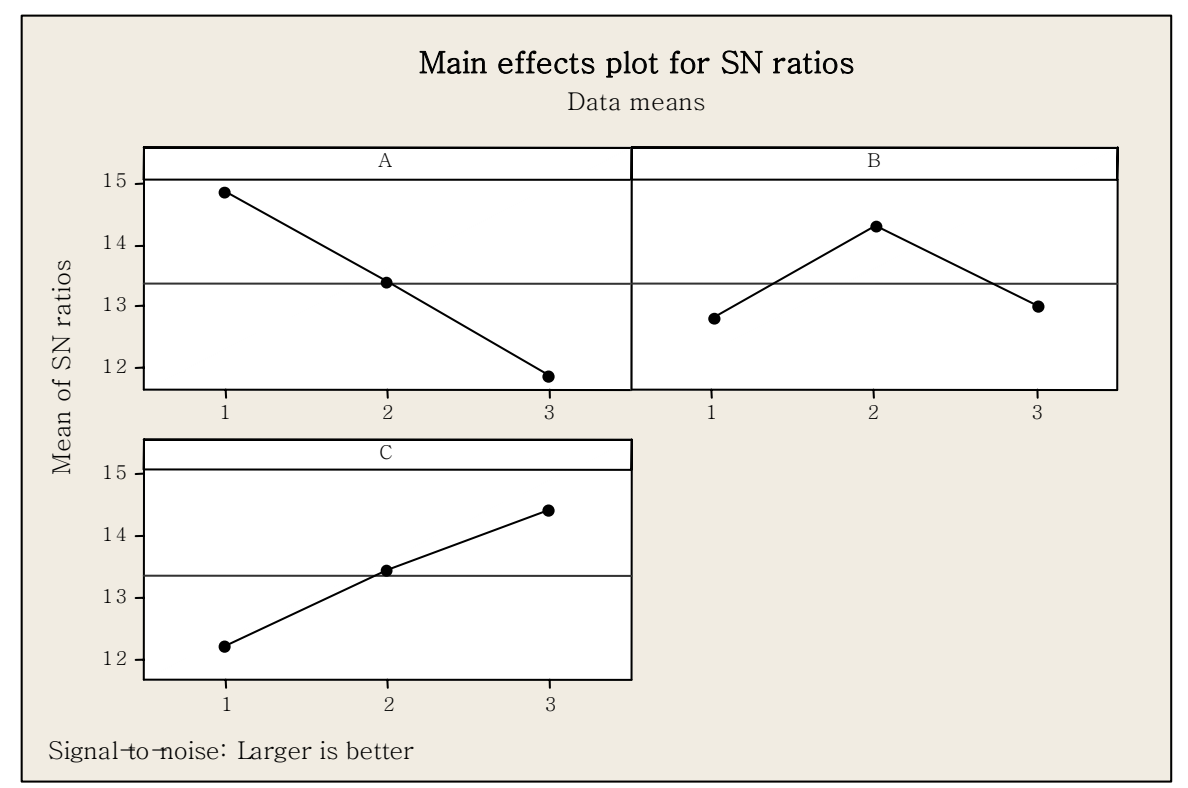

Fig. 3 Main effects plot for $\mathrm{S} / \mathrm{N}$ ratio

Table 6 Response for $\mathrm{S} / \mathrm{N}$ ratios; larger is better

\begin{tabular}{|c|c|c|c|}
\hline Level & A & B & C \\
\hline 1 & 14.86 & 12.89 & 12.23 \\
\hline 2 & 13.39 & 14.29 & 13.69 \\
\hline 3 & 8.19 & 12.99 & 14.43 \\
\hline Delta & 6.67 & 1.40 & 2.20 \\
\hline Rank & 1 & 3 & 2 \\
\hline
\end{tabular}

\subsubsection{Adequacy of the model}

The model checked for the adequacy by using ANOVA i.e. Analysis of Variance Method.

As per ANOVA, the value of $\mathrm{P}$ should be less than 0.05 for every parameter for the desired adequacy \& it has been confirmed that the model is adequate from the
Table 7 Response table for means

\begin{tabular}{|c|c|c|c|}
\hline Level & A & B & C \\
\hline 1 & 5.59 & 4.38 & 4.09 \\
\hline 2 & 4.75 & 5.29 & 4.80 \\
\hline 3 & 3.92 & 4.58 & 5.35 \\
\hline Delta & 1.67 & 0.91 & 1.26 \\
\hline Rank & 1 & 3 & 2 \\
\hline
\end{tabular}

below results.

General Linear Model: SNRA1 versus A, B, C.

\subsubsection{Optimum process parameters}

Regardless of the category of the quality characteristic, a greater $\mathrm{S} / \mathrm{N}$ ratio corresponds to better quality 
characteristics. Therefore, the optimal level with the greatest $\mathrm{S} / \mathrm{N}$ ratio. The optimal levels of process are: From the graph of $\mathrm{S} / \mathrm{N}$ Ratio \& mean values

$$
\begin{array}{lll}
\text { Current - } & \text { A 1 } & =160 \mathrm{~A} \\
\text { Voltage - } & \text { B 2 } & =19 \mathrm{~V} \\
\text { Wire Speed - } & \text { C 3 } & =12 \mathrm{~m} / \mathrm{min} .
\end{array}
$$

\section{Conclusion}

The present study is carried to discuss an application of the Taguchi Method for obtaining the maximum length of penetration. We have conducted various trials for the optimization of process parameters \& reach to following conclusion.

1) Optimization of process parameters can be effectively done by using 3 levels, 3 factors \& L9 orthogonal array

2) Better penetration observed is $7.2334 \mathrm{~mm}$ at Current $160 \mathrm{~A}$, Voltage $19 \mathrm{~V}$, Wire Speed $12 \mathrm{M} / \mathrm{min}$

\section{Acknowledgement}

The authors would like to acknowledge the support for experimental set up rendered by Mr. Shekhar Thorat (Executive Director \& Unit Head) of M/s Metalman Auto Pvt. Ltd., Aurangabad. Maharashtra, India.

\section{References}

1. Weldability, An Introduction to MIG welding WWS Group

2. The Linde Group (Formerly British Oxygen Company Ltd.), AU: IPRM 200, Section 8: Consumables

3. ISO 15609-1:2004, Specification and qualification of welding procedures for metallic materials - Welding procedure specification

4. S.D.Ambekar, S.R.Wadhokar, Parametric optimization of gas metal arc welding process by using Taguchi method on stainless steel AISI 410, International Journal of Research in Modern Engineering and Emerging Technology, 3 (1) (2015)

5. Pradeep Deshmukh1, S. N. Teli, Parametric optimization of SAW Welding Parameters using Taguchi L9 array, International Journal of Engineering, Business and Enterprise Applications, (2014), 45s-57s

6. P. Sreeraj, T. Kannan, Subhasis Maji, Prediction and optimization of weld bead geometry in gas metal arc welding process using RSM and fmincon, Journal of Mechanical Engineering Research, 5 (8) (2013), 154-165, DOI 10.5897/ JMER2013.0292

7. S.Utkarsh, P. Neel, Mayank T Mahajan, P.Jignesh4, R. B.Prajapati, Experimental investigation of MIG welding for ST-37 using design of experiment, International Journal of Scientific and Research Publications, 4 (5) (2014)

8. Satyaduttsinh P. Chavda, JayeshV. Desai, Tushar M. Patel, A review on optimization of MIG Welding parameters using Taguchi's DOE method, International Journal of Engineering and Management research, 1 (2014), 16-21 